Article

\title{
Tuning of Schottky Barrier Height at NiSi/Si Contact by Combining Dual Implantation of Boron and Aluminum and Microwave Annealing
}

\author{
Feng Sun ${ }^{1}$, Chen Li ${ }^{1}$, Chaochao Fu ${ }^{1}$, Xiangbiao Zhou ${ }^{1}$, Jun Luo ${ }^{2}{ }^{\mathbb{D}}$, Wei Zou ${ }^{3}$, Zhi-Jun Qiu ${ }^{1, *}$ \\ and Dongping $\mathrm{Wu}^{1, *}$ \\ 1 State Key Laboratory of ASIC and System, Fudan University, Shanghai 200433, China; \\ 15210720083@fudan.edu.cn (F.S.); 16110720066@fudan.edu.cn (C.L.); 12110720010@fudan.edu.cn (C.F.); \\ 12212020051@fudan.edu.cn (X.Z.) \\ 2 Key Laboratory of Microelectronic Devices and Integrated Technology, Institute of Microelectronics, \\ Chinese Academy of Science, Beijing 100029, China; luojun@ime.ac.cn \\ 3 Process Application, Applied Materials, Inc., Gloucester, MA 01930, USA; Wei_Zou@amat.com \\ * Correspondence: zjqiu@fudan.edu.cn (Z.-J.Q.); dongpingwu@fudan.edu.cn (D.W.); \\ Tel.: +86-21-55665243 (D.W.)
}

Received: 4 March 2018; Accepted: 21 March 2018; Published: 22 March 2018

\begin{abstract}
Dopant-segregated source/drain contacts in a p-channel Schottky-barrier metal-oxide semiconductor field-effect transistor (SB-MOSFET) require further hole Schottky barrier height (SBH) regulation toward sub- $0.1 \mathrm{eV}$ levels to improve their competitiveness with conventional field-effect transistors. Because of the solubility limits of dopants in silicon, the requirements for effective hole SBH reduction with dopant segregation cannot be satisfied using mono-implantation. In this study, we demonstrate a potential solution for further SBH tuning by implementing the dual implantation of boron (B) and aluminum (Al) in combination with microwave annealing (MWA). By using such a method, not only has the lowest hole SBH ever with $0.07 \mathrm{eV}$ in $\mathrm{NiSi} / \mathrm{n}-\mathrm{Si}$ contacts been realized, but also the annealing duration of MWA was sharply reduced to $60 \mathrm{~s}$. Moreover, we investigated the SBH tuning mechanisms of the dual-implanted diodes with microwave annealing, including the dopant segregation, activation effect, and dual-barrier tuning effect of Al. With the selection of appropriate implantation conditions, the dual implantation of $\mathrm{B}$ and $\mathrm{Al}$ combined with the MWA technique shows promise for the fabrication of future p-channel SB-MOSFETs with a lower thermal budget.
\end{abstract}

Keywords: Schottky barrier height; SB-MOSFET; dopant segregation; microwave annealing; dual implantation

\section{Introduction}

Schottky-barrier metal-oxide semiconductor field-effect transistors (SB-MOSFETs) [1], also known as metallic source/drain (S/D) MOSFETs (MSD-MOSFETs) [2], have emerged as potential candidates for replacing the conventional $\mathrm{p}-\mathrm{n}$ junction in an S/D contact. SB-MOSFETs exhibit (1) lower parasitic resistance and capacitance; (2) a shallower junction depth; and (3) a shorter response time than conventional MOSFETs [1,3]. However, to further improve their performance, the effective Schottky barrier height (SBH) of SB-MOSFETs must be reduced to below $100 \mathrm{meV}$ to overcome problems such as low drive currents and high contact resistance during scaling [4-6]. To meet this objective, various metal silicides have been introduced, including nickel silicide because of its low formation temperature and limited Si consumption [7]. Dopant segregation (DS) [8] schemes aiming at SBH interfacial 
property regulation have also been implemented, including the use of silicide as a diffusion source (SADS) $[7,9,10]$, silicide-induced dopant segregation (SIDS) [7,11], and other modified schemes [12].

For n-channel SB-MOSFET S/D contacts, an electron SBH $\left(\varphi_{\mathrm{bn}}\right)$ of $0.07 \mathrm{eV}$ has been achieved in NiSi/p-Si contacts via arsenic (As) DS [7,11]. Other dopants, such as sulfur [13], selenium [14], and antimony [15], have also been employed for effective $\varphi_{\mathrm{bn}}$ tuning using various mechanisms. For p-channel SB-MOSFET S/D contacts, the extreme hole SBH ( $\left.\varphi_{\mathrm{bp}}\right)$ achieved remains $0.11 \mathrm{eV}$ in $\mathrm{NiSi} / \mathrm{n}-\mathrm{Si}$ contacts via boron (B) DS [7,12]. Because of the solubility limit of B in silicon, there is little room to further exploit the capacity for SBH regulation using mono-implantation of $\mathrm{B}$ [11]. It has been reported that aluminum (Al) DS can reduce the $\varphi_{\text {bp }}$ value to $0.11 \mathrm{eV}$ in NiSi/p-Si contacts [16-18] and that indium DS can reduce this value to $0.16 \mathrm{eV}$ [19]. According to Shannon, a p-type dopant could also be used to tune $\varphi_{\mathrm{bp}}$ in an n-type substrate and vice versa [20]. Hence, $\mathrm{Al}$ is an ideal alternative for introduction into a p-channel metal S/D to achieve further $\varphi_{\mathrm{bp}}$ reduction.

The microwave annealing (MWA) process has gradually been accepted as an alternative annealing method because of its various beneficial properties, such as selective annealing [21], reduced diffusion [22], and higher activation of the dopant at a relatively lower temperature [23] compared with conventional thermal annealing methods, such as furnace annealing and rapid thermal annealing (RTA). The capacity toward effective SBH regulation in a DS NiSi/Si contact was improved when using 600-s MWA instead of 600-s RTA at a lower temperature [11]. However, to improve the competitiveness of MWA for SBH tuning, the duration of MWA should be reduced to achieve further reduction of the thermal budget. Previous works have shown that microwave absorption can be enhanced in silicon by using heavier ions (B/As) or Ge/Si pre-amorphization implantation [24], which would lead to further defect generation [23]. Therefore, a feasible strategy to enhance the absorption of microwaves is to increase the defect density by implanting an additional dopant, for which $\mathrm{Al}$ is an ideal candidate.

In this work, we propose a novel solution to achieve further effective SBH tuning and MWA absorption enhancement by implementing dual implantation of $\mathrm{B}$ and $\mathrm{Al}$ with varying implantation energies. The SIDS method was used for further thermal budget control [7,11], and the corresponding SBH regulation mechanisms were investigated.

\section{Materials and Methods}

Four-inch n-type silicon wafers (100) with resistivity of 1-10 $\Omega \cdot \mathrm{cm}$ were used for the device fabrication. Following the RCA clean to remove any contaminants, a 200-nm-thick $\mathrm{SiO}_{2}$ isolation layer was grown on each substrate using low-pressure chemical vapor deposition. The active regions were defined using $75-\mu \mathrm{m}$-radius circular patterns. B with an energy of $1 \mathrm{keV}$ and $\mathrm{Al}$ with an energy ranging from 2 to $10 \mathrm{keV}$ were sequentially implanted into the substrates at equal doses of $1 \times 10^{15} \mathrm{~cm}^{-2}$ with a Varian High Current Implanter (Applied Materials, Inc., Gloucester, MA, USA). The detailed implantation conditions are listed in Table 1. Next, an HF dip was used to remove the native oxide layer, and a 40-nm-thick Ni layer was sputter-deposited onto the surface. The wafers were then sliced into square samples with dimensions of $22 \mathrm{~mm} \times 22 \mathrm{~mm}$ and divided into four groups named $\mathrm{N} 1$, $\mathrm{N} 2$, N3, and N4 according to their implantation conditions. MWA was performed in an AXOM-200 (DSG Technologies, Inc., Santa Clara, CA, USA) octagonal MWA chamber at $5.8 \mathrm{GHz}$. Each sample was separately heated in an $\mathrm{N}_{2}$ atmosphere for $60 \mathrm{~s}$ at various MWA power conditions $(1120,1750$, 2590,2800 , and $3500 \mathrm{~W}$ ). The susceptor-assisted method [22,25,26] was employed to aid the heating of the substrate during the MWA process. After the annealing process, residual Ni was removed by immersing the samples in a 2:1 $\mathrm{H}_{2} \mathrm{SO}_{4}: \mathrm{H}_{2} \mathrm{O}_{2}$ solution at a constant temperature of $120^{\circ} \mathrm{C}$ for $600 \mathrm{~s}$.

\section{Results and Discussion}

To characterize the Schottky diodes, the current-voltage (I-V) and capacitance-voltage (C-V) methods were both implemented. Using standard C-V measurements for SBH extraction $[9,11]$, the $\mathrm{C}-\mathrm{V}$ curves were converted into $1 / \mathrm{C}^{2}-\mathrm{V}$ curves, where the intercept and slope of the linear fit were used to determine the SBH of the diodes $[27,28]$. In extracting the SBH for an n-type substrate, 
the SBH is denoted as $\varphi_{\mathrm{bn}}$. Because $\varphi_{\mathrm{bn}}+\varphi_{\mathrm{bp}}=1.12 \mathrm{eV}$, an increase in $\varphi_{\mathrm{bn}}$ means a decrease in $\varphi_{\mathrm{bp}}$ and vice versa. Figure 1 presents the $\mathrm{I}-\mathrm{V}$ and $1 / \mathrm{C}^{2}-\mathrm{V}$ characteristics classified by implantation conditions. The extracted $\varphi_{\mathrm{bn}}$ values are listed in Table 1 and depicted in Figure 2. As shown in Figure $1 \mathrm{a}-\mathrm{c}$, a monolithic trend of decreasing reverse currents with increasing MWA power was observed, which is similar to the trend observed in our previous research [11]. This tendency indicates a positive correlation between the $\mathrm{SBH}$ and microwave power and that more thorough activation and segregation of dopants likely occurs under higher-power microwave radiation. Moreover, the apparent reduction of the reverse currents in the samples with $\mathrm{Al}$ implantation suggests that the dual-implanted diodes exhibited an improved ability toward $\varphi_{\text {bn }}$ elevation compared with $\mathrm{N} 1$, which is in agreement with the SBH results presented in Figure 2. The high values of $\varphi_{\text {bn }}$ beyond $1.02 \mathrm{eV}$ obtained for the dual-implanted specimens surpass extreme values in the literature obtained using single B implantation [7,12]. In other words, we achieved sub- $0.1 \mathrm{eV} \varphi_{\mathrm{bp}}$ values via dual implantation for a $\mathrm{NiSi} / \mathrm{n}$-Si contact, which is ideal for a p-channel SB-MOSFET. This phenomenon can be attributed to the segregation of $\mathrm{Al}$ at the silicide/substrate interface, which enables the saturation limits of $\mathrm{SBH}$ regulation by $\mathrm{B}$ implantation to be overcome, such that the limit of dipoles generation at the interface is confined by the solubility of B in silicon. Further details of this regulation scheme will be discussed in the following sections.
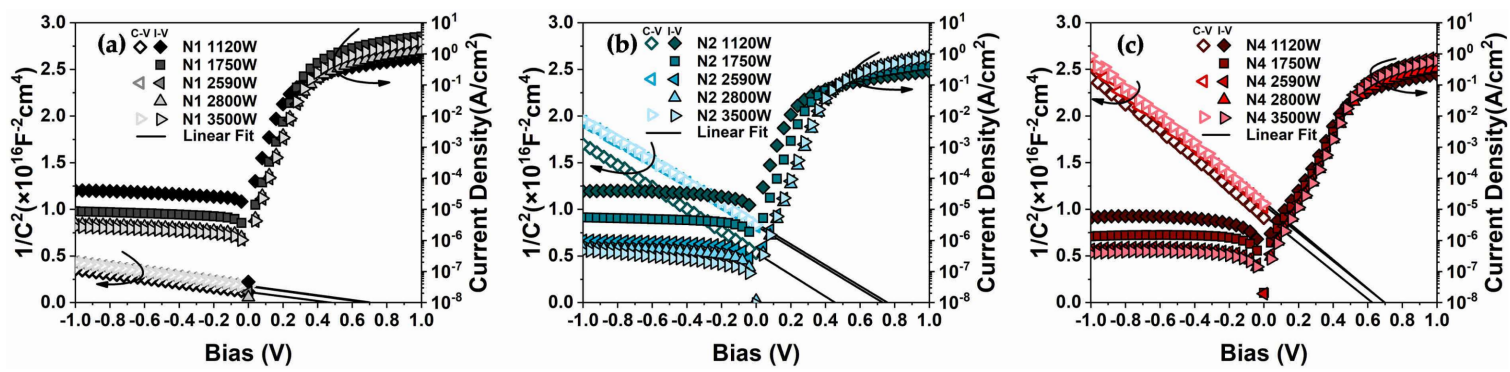

Figure 1. Current-voltage (I-V) and $1 / \mathrm{C}^{2}-\mathrm{V}$ characteristics of (a) N1, (b) N2, and (c) N4 samples.

Table 1. Effect of implantation conditions and microwave annealing (MWA) power on effective $\varphi_{\mathrm{bn}}$.

\begin{tabular}{|c|c|c|c|c|c|c|c|}
\hline \multirow{3}{*}{ Sample No. } & \multicolumn{2}{|c|}{ Implant Species } & \multicolumn{5}{|c|}{ MWA Power } \\
\hline & B & Al & $1120 \mathrm{~W}$ & $1750 \mathrm{~W}$ & $2590 \mathrm{~W}$ & $2800 \mathrm{~W}$ & $3500 \mathrm{~W}$ \\
\hline & \multicolumn{2}{|c|}{ Implant Energy (keV) } & \multicolumn{5}{|c|}{$\varphi_{\mathrm{bn}}(\mathrm{eV})$} \\
\hline N1 & 1 & - & 0.73 & 0.85 & 0.92 & 0.94 & 0.96 \\
\hline N2 & 1 & 2 & 0.73 & 0.82 & 1.02 & 1.04 & 1.05 \\
\hline N3 & 1 & 4 & 0.88 & 0.97 & 1.01 & 1.01 & 1.01 \\
\hline N4 & 1 & 10 & 0.92 & 0.98 & 1.00 & 1.00 & 1.00 \\
\hline
\end{tabular}

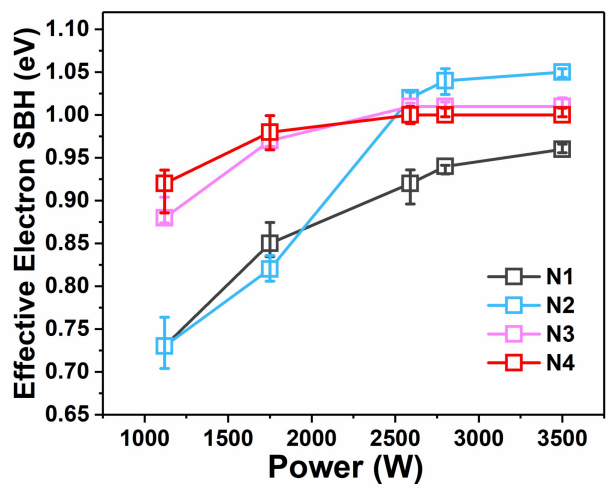

Figure 2. Effective $\varphi_{\mathrm{bn}}$ as a function of MWA power. SBH: Schottky barrier height. 
Additionally, an extended range of the rectification ratio [16] for the N2 samples was observed, as shown in Figure 1a, whereas the range of the N4 diodes was lower. This phenomenon is consistent with the $1 / C^{2}-V$ characteristics, indicating that $\varphi_{b n}$ increased to various degrees upon increasing the MWA power (from 0.73 to $1.05 \mathrm{eV}$ for $\mathrm{N} 2$ and from 0.93 to $1.00 \mathrm{eV}$ for N4). As shown in Figure 2, the effective SBH curves of the dual-implanted diodes converged below $2590 \mathrm{~W}$ and diverged again above this value. For lower microwave power $(1120 \mathrm{~W})$, the samples with higher Al implantation energy exhibited reduced $\varphi_{\mathrm{bn}}$ tuning ability than those with lower implantation energy. At higher MWA power $(3500 \mathrm{~W})$, the opposite trend was observed. These results imply an inverse relationship between the $\mathrm{Al}$ implantation energy and $\varphi_{\text {bn }}$ tuning ability. To further investigate this phenomenon, Raman spectra of the samples prepared using MWA powers of 1120 and $3500 \mathrm{~W}$ were obtained. As shown in Figure 3a,b, obvious NiSi peaks $[11,29]$ were detected in all the selected samples, indicating conversion of the nickel silicides into monosilicides. As the silicides at both ends of the MWA power range were verified to be $\mathrm{NiSi}$, it is reasonable to conclude that all the silicides of the diodes in that range were monosilicides. Therefore, the SBH tuning scheme of dual-implanted diodes shows no relation with the nickel silicide phase, thereby necessitating further investigations. Moreover, the peak annealing temperature during the MWA process was determined to be below $344^{\circ} \mathrm{C}$, which is far below the lowest record of $400{ }^{\circ} \mathrm{C}$ using conventional thermal annealing methods [30], even when accounting for measurement errors produced by the infrared pyrometer [11]. Previous studies have demonstrated that the lower annealing temperature of the MWA process results from its unique non-thermal effect, which reduces the bonding activation energy during the recombination process $[23,31]$. Thus, a non-thermal effect could play a crucial role in reducing the temperature during nickel silicide formation.
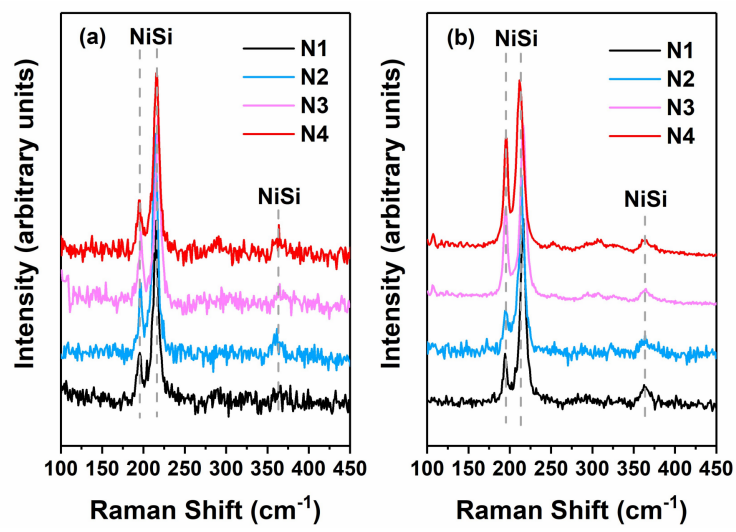

Figure 3. Raman spectra of samples prepared using MWA powers of (a) $1120 \mathrm{~W}$ and (b) $3500 \mathrm{~W}$.

To further explore the SBH tuning mechanism of MWA dual implantation, secondary-ion mass spectroscopy (SIMS) was applied. Figure 4 presents the depth profiles of B and Al in the N1, N2, and N4 samples. The NiSi layer of the N1 samples $(80 \mathrm{~nm})$ was relatively thinner than that of the dual-implanted samples $(90 \mathrm{~nm})$. Based on the Raman results that the silicides have been confirmed as monosilicides, the thickness difference presumably arose from the occasional non-uniform deposition of Ni during the sputtering, which resulted in a rough interface after annealing. The distribution patterns of B and Al in Figure 4 are distinct, which can be attributed to the lower solubility of B in silicides [7], which resulted in a more protruding profile. In contrast, for $\mathrm{Al}$, no obvious segregation peaks were detected at the $\mathrm{NiSi} / \mathrm{Si}$ interface, which is similar to the observation by Sinha that the distribution curves tend to be more flattened with higher doses of $\mathrm{Al}$, as the solubility of $\mathrm{Al}$ in NiSi $\left(\sim 6 \times 10^{20} \mathrm{~cm}^{-3}\right)$ is higher than that in $\mathrm{Si}\left(\sim 2 \times 10^{19} \mathrm{~cm}^{-3}\right)$ [32]. As the dose of $\mathrm{Al}$ in our work $\left(1 \times 10^{15} \mathrm{~cm}^{-2}\right)$ was even higher than that in Sinha's work $\left(2 \times 10^{14} \mathrm{~cm}^{-2}\right)$, Al presented a higher concentration at the interface, resulting in an even more covered segregation peak. The Al peak for the N4 samples at a depth of approximately $50 \mathrm{~nm}$ is assigned as the as-implanted Al peak in Si [33]. 
In addition, the long diffusion length in silicon is partly attributed to the diffusivity enhancement of Al by extrinsic B doping [34]. The disparity of the peak concentration at the interface between the dopants was credited to the solubility of B in Si exceeding that of Al [35].

Furthermore, when examining the samples prepared with an MWA power of $1120 \mathrm{~W}$, a complex pattern of the concentrations of $\mathrm{B}$ and $\mathrm{Al}$ at the interface was observed. Compared with $\mathrm{N} 1, \mathrm{~N} 4 \mathrm{had}$ a higher concentration of $\mathrm{B}$ at the interface, suggesting improvement of the segregation of $\mathrm{B}$ with the additional $\mathrm{Al}$ implantation. Comparison of $\mathrm{N} 1$ and $\mathrm{N} 2$ revealed that the accumulated concentration of both dopants at the interface was not sufficiently high to implement effective $\mathrm{SBH}$ tuning, with the $\varphi_{\mathrm{bn}}$ value remaining at $0.73 \mathrm{eV}$, which was same as the original SBH result of NiSi/Si contact [7]. Potential mechanisms driving this behavior need to be investigated. First-principles calculations indicate that dopants' substitution of $\mathrm{Si}$ atoms approximately within the first $\mathrm{Si}$ monolayer from the interface of NiSi/Si could stimulate dipoles for band bending and $\mathrm{SBH}$ regulation $[7,11,36]$. Therefore, this variation may be related to the activation of dopants at the interface. Considering the implantation energy difference of $\mathrm{Al}$, we believe various degrees of amorphization may lead to different levels of dopant activation in both mono- and dual-implanted diodes. Compared with the N2 samples with the implantation energy of $2 \mathrm{keV}$, the $\mathrm{N} 4$ samples were characterized by heavier and deeper amorphous regions because of the higher implantation energy of $\mathrm{Al}$ at $10 \mathrm{keV}$, which produced a projected range of approximately $20 \mathrm{~nm}$ [37]. The mean projected range can also be determined from the location of the first crest of $\mathrm{Al}$ in Figure 4, which appeared at the same position as the as-implanted $\mathrm{Al}$ peak. Given the deeper amorphous region produced by the higher implantation energy of $\mathrm{Al}$, where strong rotation of dipoles occurs in response to the alternating electromagnetic field, the dielectric polarization loss effect was greatly induced [23], thereby enhancing absorption of microwaves during the MWA process. Combined with the intensified non-thermal effect reducing the dopant activation energy, the dopants were activated to a large extent. In contrast, for the N2 sample, the projected range of implanted $\mathrm{Al}$ with an implantation energy of $2 \mathrm{keV}$ remained the same as that of implanted B with an implantation energy of $1 \mathrm{keV}(6 \mathrm{~nm})$ [37]. This shallower amorphous layer was rapidly consumed during the formation of nickel silicide. It has been reported that both the dielectric polarization loss effect and non-thermal effect vanish in silicon after the defects are fully repaired [23]. Therefore, sufficient microwave absorption could not be induced in N2 to enable the activation of the dual dopants, resulting in an insignificant non-thermal effect. Figure 4 also shows that the peak concentrations of $\mathrm{B}$ in both $\mathrm{N} 1$ and $\mathrm{N} 2$ were far below the saturation point.

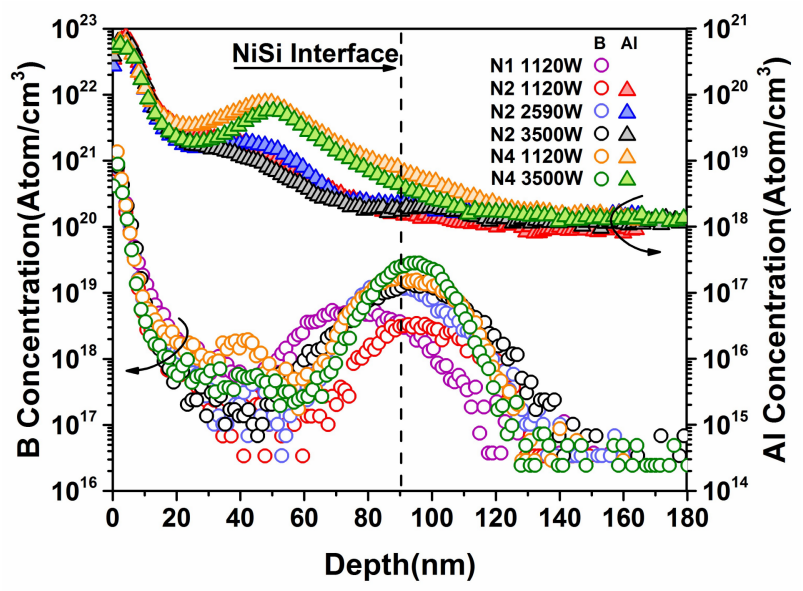

Figure 4. Separated SIMS (secondary-ion mass spectroscopy) depth profiles of Al and B in selected samples.

A reversed correlation must be clarified when the MWA power reached $3500 \mathrm{~W}$. As shown in Figure 4, higher concentrations of B and Al were segregated at the interface for N4 than for N2, even resulting in a narrower width of the segregated region of B. However, N2 showed better regulation 
toward $\varphi_{\mathrm{bn}}$ elevation, achieving a value of $1.05 \mathrm{eV}$, which is $50-\mathrm{meV}$ higher than that obtained for $\mathrm{N} 4$. To obtain a better understanding of the aforementioned reversed correlation between $\varphi_{\mathrm{bn}}$ and the $\mathrm{Al}$ implantation energy, the N2 sample prepared using an MWA power of $2590 \mathrm{~W}$ was included for comparison. Except for being inadequately activated in the N2 samples prepared using MWA powers below $2590 \mathrm{~W}$, no differences were observed in the distributions of B in the selected samples. However, an obvious discrepancy was observed between N2 and N4 as shown in Figure 4: a higher implantation energy of $\mathrm{Al}$ resulted in a higher $\mathrm{Al}$ concentration at the interface accompanied by a higher density of $\mathrm{Al}$ remaining in the NiSi film. Previous studies have indicated that $\mathrm{Al}$ has a dual-barrier tuning effect [18,38], including reducing $\varphi_{\mathrm{bn}}$ when incorporated with nickel silicide [39-41] and reducing $\varphi_{\mathrm{bp}}$ at $\mathrm{NiSi} / \mathrm{Si}$ interfaces. It has been reported that the incorporation of $\mathrm{Al}$ in $\mathrm{NiSi}$ could reduce the metal work function of NiSi by up to $400 \mathrm{meV}$ [39]. This finding was further confirmed by implanting carbon before Al combined with DS methods, which suppressed the diffusion of $\mathrm{Al}$ and sharpened its $\varphi_{\mathrm{bn}}$ reduction effect [38]. Thus, we attribute the aforementioned reversed tendency of SBH tuning with $\mathrm{Al}$ implantation energy to the different $\mathrm{Al}$ contents in $\mathrm{NiSi}$, which inordinately affected the effective elevation of the SBH.

Specific details about the SBH regulation schemes of additional implanted $\mathrm{Al}$ are presented in Figure 5. First, for MWA powers under $2950 \mathrm{~W}$ as shown in Figure 5, because Al was already saturated at the interface, no further concentration enhancement could be achieved by further increasing the power. Counterbalanced by the $\varphi_{\text {bn }}$ reduction from $\mathrm{Al}$ in NiSi, $\mathrm{Al}$ showed weak control over $\varphi_{\text {bn }}$ elevation. Effective SBH tuning is primarily affected by activated $B$ at the interface. In addition, a higher implantation energy of $\mathrm{Al}$ also contributed to stronger activation and segregation of $\mathrm{B}$ for a deeper amorphous region. Thus, N4 showed better regulation toward effective $\varphi_{\mathrm{bn}}$ elevation than N2. Second, as the MWA power increased above 2950 W, as shown in Figure 5, B was adequately activated and segregated such that increasing the MWA power alone could not result in remarkable improvement. Combined with the highly segregated $\mathrm{B}$, the $\varphi_{\mathrm{bn}}$ elevation capacity of $\mathrm{Al}$ started emerging. For the N2 sample, a $\varphi_{\mathrm{bn}}$ of $1.05 \mathrm{eV}$ was achieved. However, although the tendency of draining $\mathrm{Al}$ in NiSi with increasing MWA power was observed in both $\mathrm{N} 2$ and N4, the effect of $\varphi_{\mathrm{bn}}$ elevation of Al remained insufficiently intense to overcome the $\varphi_{\text {bn }}$ reduction effect in N4. As observed in Figure 4, compared with N2, substantial accumulation of Al still occurred above the interface in N4 after diffusion with promoted microwave radiation, which presumably affected SBH regulation [42]. In our case, with an MWA power of $3500 \mathrm{~W}$, the calculated dose of $\mathrm{Al}$ from $50 \mathrm{~nm}$ above the interface and to that varied from $3.92 \times 10^{13} \mathrm{~cm}^{-2}(\mathrm{~N} 2)$ to $1.33 \times 10^{14} \mathrm{~cm}^{-2}(\mathrm{~N} 4)$ depending on the Al implantation energy of the device. This difference most likely resulted in an effective reduction of the work function of $\mathrm{N} 4$ for NiSi. Thus, an inconspicuous effect of $\varphi_{\mathrm{bn}}$ elevation was observed for N4 despite the higher concentration of $\mathrm{Al}$ at the interface.

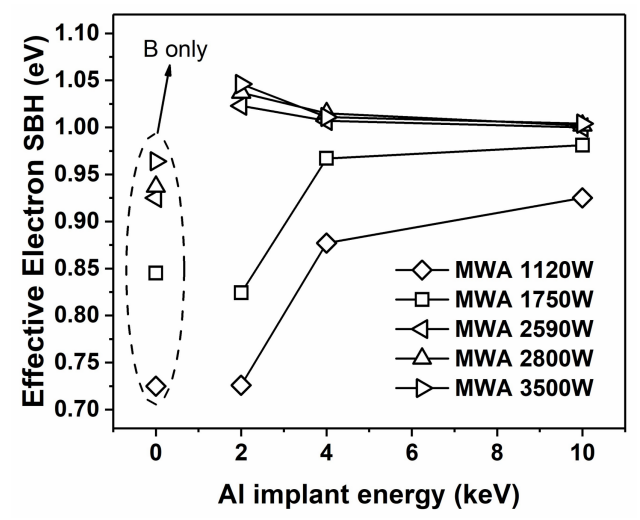

Figure 5. $\varphi_{\mathrm{bn}}$ tuning schemes of dual implantation associated with $\mathrm{Al}$ implantation energy. The points encircled by the dashed line represent samples implanted with B only. The squares represent the first stage, and the triangles represent the second stage. 
Therefore, taking the two stages into consideration, the trade-off between the implantation energy and MWA power was attributed to the contradiction between the reduction and elevation of $\varphi_{\mathrm{bn}}$ of $\mathrm{Al}$ as well as that between the concentration of $\mathrm{Al}$ remaining in $\mathrm{NiSi}$ and that accumulated at the $\mathrm{NiSi} / \mathrm{Si}$ interface. To overcome this contradiction and achieve higher $\varphi_{\mathrm{bn}}$ with lower MWA power, a thinner film of silicide [16] or a lower dose of Al [18] could be employed to sharpen the segregation peak at the NiSi/Si interface in future applications.

\section{Conclusions}

By implementing B and Al dual implantation, we demonstrate a potential solution for further effective $\varphi_{\mathrm{bp}}$ reduction to sub-0.1 eV levels and MWA absorption enhancement in NiSi/n-Si contacts. We report the lowest $\varphi_{\mathrm{bp}}$ achieved thus far of $0.07 \mathrm{eV}$ at $500{ }^{\circ} \mathrm{C}(3500 \mathrm{~W})$ in a NiSi/n-Si contact and a $\varphi_{\mathrm{bp}}$ of $0.2 \mathrm{eV}$ at sub-350 ${ }^{\circ} \mathrm{C}(1120 \mathrm{~W})$. Compared with 600-s MWA using mono-implantation, a compressed microwave annealing duration of $60 \mathrm{~s}$ was also achieved via the dual-implantation scheme. The SBH tuning schemes of the dual-implanted diodes were investigated, and higher energy of $\mathrm{Al}$ appears to induce microwave absorption, thereby resulting in high dopant activation and segregation. In addition, we explored the trade-off between the implantation energy of Al and MWA power in dual-implanted diodes. The contradiction of the reduction of the $\mathrm{SBH}$ of $\mathrm{Al}$ in NiSi and its elevation at NiSi/Si interfaces could potentially be solved by applying thinner silicides or a lower dose of Al. Benefiting from the unique properties arising from MWA, various combinations of dopants and triple-, quad-, or multi-implantation schemes accompanied by a lower thermal budget could be developed to achieve further SBH regulation.

Acknowledgments: This work was supported by the National Natural Science Foundation of China (Nos. 61474028, 61774042), Shanghai Municipal Natural Science Foundation (No. 17ZR1446500), National S and T Project 02 (No. 2013ZX02303-004), and the "First-Class Construction" project of Fudan University.

Author Contributions: Feng Sun and Dongping Wu conceived and designed the experiments; Feng Sun, Chen Li, Chaochao Fu, Xiangbiao Zhou, Jun Luo, and Wei Zou performed the experiments; Jun Luo and Wei Zou contributed sputtering and ion implantation equipment, respectively; Feng Sun and Zhi-Jun Qiu analyzed the data; all the authors wrote the paper.

Conflicts of Interest: The authors declare no conflict of interest.

\section{References}

1. Larson, J.M.; Snyder, J.P. Overview and Status of Metal Source/Drain Schottky Barrier MOSFET Technology. IEEE Trans. Electron Devices 2006, 53, 1048-1058. [CrossRef]

2. Dubois, E.; Larrieu, G. Measurement of low Schottky barrier heights applied to metallic source/drain metal-oxide-semiconductor field effect transistors. J. Appl. Phys. 2004, 96, 729-737. [CrossRef]

3. Fritze, M.; Chen, C.L.; Calawa, S.; Yost, D.; Wheeler, B.; Wyatt, P.; Keast, C.L.; Snyder, J.; Larson, J. High-speed Schottky-barrier pMOSFET with $\mathrm{fT}=280 \mathrm{GHz}$. IEEE Electron Device Lett. 2004, 25, 220-222. [CrossRef]

4. Larrieu, G.; Dubois, E.; Valentin, R.; Breil, N.; Danneville, F.; Dambrine, G.; Raskin, J.-P.; Pesant, J.C. Low temperature implementation of dopant-segregated band-edge metallic S/D junctions in thin-body SOI p-MOSFETs. In Proceedings of the IEEE International Electron Devices Meeting, Washington, DC, USA, 10-12 December 2007; pp. 147-150.

5. Xiong, S.; King, T.J.; Bokor, J. A comparison study of symmetric ultrathin-body double-gate devices with metal source/drain and doped source/drain. IEEE Trans. Electron Devices 2005, 52, 1859-1867. [CrossRef]

6. Knoch, J.; Zhang, M.; Mantl, S.; Appenzeller, J. On the performance of single-gated ultrathin-body SOI Schottky-barrier MOSFETs. IEEE Trans. Electron Devices 2006, 53, 1669-1674. [CrossRef]

7. Qiu, Z.; Zhang, Z.; Östling, M.; Zhang, S. A Comparative Study of Two Different Schemes to Dopant Segregation at NiSi/Si and PtSi/Si Interfaces for Schottky Barrier Height Lowering. IEEE Trans. Electron Devices 2008, 55, 396-403. [CrossRef] 
8. Kinoshita, A.; Tsuchiya, Y.; Yagishita, A.; Uchida, K.; Koga, J. Solution for high-performance Schottky-source/drain MOSFETs: Schottky barrier height engineering with dopant segregation technique. In Proceedings of the Symposium on VLSI Technology, Honolulu, HI, USA, 15-17 June 2004; pp. 168-169. [CrossRef]

9. Zhang, Z.; Qiu, Z.; Liu, R.; Östling, M.; Zhang, S.L. Schottky-barrier height tuning by means of ion implantation into preformed silicide films followed by drive-in anneal. IEEE Electron Device Lett. 2007, 28, 565-568. [CrossRef]

10. Luo, J.; Qiu, Z.J.; Zhang, D.W.; Hellstrom, P.E.; Östling, M.; Zhang, S.L. Effects of carbon on schottky barrier heights of NiSi modified by dopant segregation. IEEE Electron Device Lett. 2009, 30, 608-610. [CrossRef]

11. Fu, C.; Zhou, X.; Wang, Y.; Xu, P.; Xu, M.; Wu, D.; Luo, J.; Zhao, C.; Zhang, S.-L. Schottky Barrier Height Tuning via the Dopant Segregation Technique through Low-Temperature Microwave Annealing. Materials 2016, 9, 315. [CrossRef] [PubMed]

12. Deng, J.; Liu, Q.; Zhao, C.; Li, J.; Wang, W.; Chen, D.; Ye, T.; Luo, J. A modified scheme to tune the Schottky Barrier Height of NiSi by means of dopant segregation technique. Vacuum 2014, 99, 225-227. [CrossRef]

13. Wong, H.; Chan, L.; Samudra, G.; Yeo, Y. Effective Schottky Barrier Height Reduction Using Sulfur or Selenium at the NiSi/n-Si (100) Interface for Low Resistance Contacts. Interface 2007, 28, 2007-2009. [CrossRef]

14. Wong, H.S.; Chan, L.; Samudra, G.; Yeo, Y.C. Low Schottky barrier height for silicides on n-type Si (100) by interfacial selenium segregation during silicidation. Appl. Phys. Lett. 2008, 93, 2006-2009. [CrossRef]

15. Wong, H.-S.; Chan, L.; Samudra, G.; Yeo, Y.-C. Sub-0.1-eV effective Schottky-barrier height for NiSi on n-type $\mathrm{Si}$ (100) using antimony segregation. IEEE Electron Device Lett. 2007, 28, 703-705. [CrossRef]

16. Sinha, M.; Chor, E.F.; Yeo, Y.-C. Tuning the Schottky barrier height of nickel silicide on p-silicon by aluminum segregation. Appl. Phys. Lett. 2008, 92, 222114. [CrossRef]

17. Sinha, M.; Member, S.; Tek, R.; Lee, P. Aluminum Implant and Segregation for Strained p-FinFETs With Silicon-Germanium Source/Drain. IEEE Trans. Electron Devices 2010, 57, 1279-1286. [CrossRef]

18. Koh, S.M.; Wang, X.; Thanigaivelan, T.; Henry, T.; Erokhin, Y.; Samudra, G.S.; Yeo, Y.C. Schottky barrier height tuning of silicides on p-type $\mathrm{Si}(100)$ by aluminum implantation and pulsed excimer laser anneal. J. Appl. Phys. 2011, 110. [CrossRef]

19. Alptekin, E.; Ozturk, M.C. Tuning of the nickel silicide schottky barrier height on p-type silicon by indium implantation. IEEE Electron Device Lett. 2009, 30, 1272-1274. [CrossRef]

20. Shannon, J.M. Control of Schottky barrier height using highly doped surface layers. Solid State Electron. 1976, 19, 537-543. [CrossRef]

21. Kitchen, H.J.; Vallance, S.R.; Kennedy, J.L.; Tapia-Ruiz, N.; Carassiti, L.; Harrison, A.; Whittaker, A.G.; Drysdale, T.D.; Kingman, S.W.; Gregory, D.H. Modern microwave methods in solid-state inorganic materials chemistry: From fundamentals to manufacturing. Chem. Rev. 2013, 114, 1170-1206. [CrossRef] [PubMed]

22. Xu, P.; Fu, C.; Hu, C.; Zhang, D.W.; Wu, D.; Luo, J.; Zhao, C.; Zhang, Z.B.; Zhang, S.L. Ultra-shallow junctions formed using microwave annealing. Appl. Phys. Lett. 2013, 102,1-5. [CrossRef]

23. Fu, C.; Wang, Y.; Xu, P.; Yue, L.; Sun, F.; Zhang, D.W.; Zhang, S.L.; Luo, J.; Zhao, C.; Wu, D. Understanding the microwave annealing of silicon. AIP Adv. 2017, 7, 1-8. [CrossRef]

24. Alford, T.L.; Thompson, D.C.; Mayer, J.W.; Theodore, N.D. Dopant activation in ion implanted silicon by microwave annealing. J. Appl. Phys. 2009, 106. [CrossRef]

25. Hu, C.; Xu, P.; Fu, C.; Zhu, Z.; Gao, X.; Jamshidi, A.; Noroozi, M.; Radamson, H.; Wu, D.; Zhang, S.L. Characterization of $\mathrm{Ni}(\mathrm{Si}, \mathrm{Ge})$ films on epitaxial SiGe(100) formed by microwave annealing. Appl. Phys. Lett. 2012, 101. [CrossRef]

26. Vemuri, R.N.P.; Gadre, M.J.; Theodore, N.D.; Chen, W.; Lau, S.S.; Alford, T.L. Susceptor assisted microwave annealing for recrystallization and dopant activation of arsenic-implanted silicon. J. Appl. Phys. 2011, 110, 34907. [CrossRef]

27. Di Bartolomeo, A.; Luongo, G.; Giubileo, F.; Funicello, N.; Niu, G.; Schroeder, T.; Lisker, M.; Lupina, G. Hybrid graphene/silicon Schottky photodiode with intrinsic gating effect. 2D Mater. 2017, 4, 25075. [CrossRef]

28. Luongo, G.; Giubileo, F.; Genovese, L.; Iemmo, L.; Martucciello, N.; Di Bartolomeo, A. I-V and C-V Characterization of a High-Responsivity Graphene/Silicon Photodiode with Embedded MOS Capacitor. Nanomaterials 2017, 7, 158. [CrossRef] [PubMed] 
29. Cichoň, S.; MacHáč, P.; Barda, B.; MacHovič, V.; Slepička, P. Raman study of Ni and Ni silicide contacts on 4H- and 6H-SiC. Thin Solid Films 2012, 520, 4378-4388. [CrossRef]

30. Jiang, Y.L.; Agarwal, A.; Ru, G.P.; Cai, G.; Li, B.Z. Nickel silicide formation on shallow junctions. Nucl. Instrum. Methods Phys. Res. Sect. B Beam Interact. Mater. Atoms 2005, 237, 160-166. [CrossRef]

31. Sivalingam, G.; Agarwal, N.; Madras, G. Kinetics of microwave-assisted polymerization of $\epsilon$-caprolactone. J. Appl. Polym. Sci. 2004, 91, 1450-1456. [CrossRef]

32. Richter, K.W.; Chandrasekaran, K.; Ipser, H. The Al-Ni-Si phase diagram. Part II: Phase equilibria between 33.3 and 66.7 at. \% Ni. Intermetallics 2004, 12, 545-554. [CrossRef]

33. Chen, L.J. Silicide Technology for Integrated Circuits; Iet: London, UK, 2004; Volume 5, ISBN 0863413528.

34. Krause, O.; Ryssel, H.; Pichler, P. Determination of aluminum diffusion parameters in silicon. J. Appl. Phys. 2002, 91, 5645-5649. [CrossRef]

35. Trumbore, F.A. Solid solubilities of impurity elements in germanium and silicon. Bell Labs Tech. J. 1960, 39, 205-233. [CrossRef]

36. Yamauchi, T.; Nishi, Y.; Tsuchiya, Y.; Kinoshita, A.; Koga, J.; Kato, K. Novel doping technology for a $1 \mathrm{~nm}$ $\mathrm{NiSi} / \mathrm{Si}$ junction with dipoles comforting Schottky (DCS) barrier. Tech. Dig. Int. Electron Devices Meet. IEDM 2007, 963-966. [CrossRef]

37. Ziegler, J.F.; Biersack, J.P.; Ziegler, M.D. The Stopping and Range of Ions in Matter, SRIM, 2013. Available online: http/ / www.srim.org (accessed on 21 March 2018).

38. Zhou, Q.; Koh, S.M.; Thanigaivelan, T.; Henry, T.; Yeo, Y.C. Contact resistance reduction for strained $\mathrm{N}$-MOSFETs with silicon-carbon source/drain utilizing aluminum ion implant and aluminum profile engineering. IEEE Trans. Electron Devices 2013, 60, 1310-1317. [CrossRef]

39. Kim, Y.H.; Cabral, C.; Gusev, E.P.; Carruthers, R.; Gignac, L.; Gribelyuk, M.; Cartier, E.; Zafar, S.; Copel, M.; Narayanan, V.; et al. Systematic study of work function engineering and scavenging effect using NiSi alloy FUSI metal gates with advanced gate stacks. In Proceedings of the IEEE IEDM Technical Digest International Electron Devices Meeting, Washington, DC, USA, 5 December 2005. [CrossRef]

40. Koh, S.M.; Zhou, Q.; Thanigaivelan, T.; Henry, T.; Samudra, G.S.; Yeo, Y.C. Novel technique to engineer aluminum profile at nickel-silicide/silicon: Carbon interface for contact resistance reduction, and integration in strained N-MOSFETs with silicon-carbon stressors. In Proceedings of the IEEE International Electron Devices Meeting (IEDM), Washington, DC, USA, 5-7 December 2011; pp. 845-848. [CrossRef]

41. Lee, R.T.P.; Liow, T.Y.; Tan, K.M.; Lim, A.E.J.; Koh, A.T.Y.; Zhu, M.; Lo, G.Q.; Samudra, G.S.; Chi, D.Z.; Yeo, Y.C. Achieving conduction band-edge Schottky barrier height for arsenic-segregated nickel aluminide disilicide and implementation in FinFETs with ultra-narrow fin widths. IEEE Electron Device Lett. 2008, 29, 382-385. [CrossRef]

42. Koh, A.T.-Y.; Lee, R.T.-P.; Lim, A.E.-J.; Lai, D.M.-Y.; Chi, D.-Z.; Hoe, K.-M.; Balasubramanian, N.; Samudra, G.S.; Yeo, Y.-C. Nickel-Aluminum Alloy Silicides with High Aluminum Content for Contact Resistance Reduction and Integration in n-Channel Field-Effect Transistors. J. Electrochem. Soc. 2008, 155, H151. [CrossRef]

(C) 2018 by the authors. Licensee MDPI, Basel, Switzerland. This article is an open access article distributed under the terms and conditions of the Creative Commons Attribution (CC BY) license (http://creativecommons.org/licenses/by/4.0/). 